Author Posting. (c) Taylor \& Francis Group, LLC, 2010.

This is the author's version of the work. It is posted here by permission of Taylor \& Francis Group, LLC

for personal use, not for redistribution.

The definitive version was published in Astropolitics, Volume 8 Issue 2, May 2010.

doi:10.1080/14777622.2010.524131 (http://dx.doi.org/10.1080/14777622.2010.524131)

\title{
Space Governance and International Cooperation
}

\author{
Nancy Gallagher \\ Center for International and Security Studies at Maryland, University of Maryland
}

Obama Administration officials have indicated that international cooperation will play a greater role in their national space policy than it did during the Bush administration. But they have not provided a clear and consistent logic specifying why the United States wants more space cooperation, what types of cooperation it will pursue, and how it will convince other countries to agree on, and comply with, accords that produce the desired policy results. Instead, their policy about space cooperation mixes elements from three different and somewhat contradictory strategic logics: a "Global Commons" logic, a "Strategic Stability" logic, and a "Space Governance for Global Security" logic. While each logic has attractive features, the Global Commons logic is unlikely to achieve significant results in a short period of time, while the Strategic Stability logic is more likely to promote competition, rather than cooperation. Following the Space Governance for Global Security logic could yield much larger dividends by using positive and negative forms of space cooperation to gain widespread support for the equitable rules and effective international institutions needed to address the central challenges identified by the 2010 National Security Strategy.

The National Space Policy and posture reviews of the Obama Administration place much greater emphasis on international cooperation than did the George W. Bush administration. ${ }^{1}$ So far, though, the new administration has not articulated a coherent and compelling strategic concept to guide its pursuit of space cooperation. Department of Defense (DOD) officials have argued that the United States needs more informal cooperation because space is increasingly "congested," "competitive," and "contested."2 State Department officials have used more diplomatic terms, saying that space is not only "congested," but also "multifaceted” and "interdependent."3 Each phrase reflects a different, somewhat contradictory way of defining the problem that space cooperation could help solve. Each also puts conceptual limits on the kinds of cooperation deemed worthy of serious U.S. consideration in ways that reduce the likelihood of international agreement on measures that would advance the administration's main policy objectives in space and its overall national security strategy.

This conceptual confusion may explain the gap between the Obama Administration's declared interest in space cooperation and the lowest-common-denominator measures that it has endorsed. For example, the United States recently announced that it would begin providing pre-launch notification for commercial and civilian satellites, but not national security satellites, and only for "the majority" of intercontinental ballistic missiles and submarine-launched ballistic missiles. ${ }^{4}$ This is a positive gesture, but it only partially fulfills the Hague Code of Conduct pledge made, but never implemented, by the Bush Administration. It falls far short of a prelaunch and post-launch notification accord signed with Russia during the Clinton Administration. 
Likewise, while stronger norms regarding responsible space behavior are a central element of the new National Space Policy, the United States has shown more interest in voluntary measures proposed by allies than in binding constraints on those countries whose space behavior most concerns the United States, and vice versa. ${ }^{5}$ Without knowing how such voluntary transparency measures and norms fit in overall U.S. national space policy and security strategies, it is hard to judge how likely they are to lead to more ambitious, robust, and effective forms of cooperation in the future.

One way to think more strategically about the role of space cooperation in achieving U.S. objectives is to evaluate different ways of conceptualizing why it might be useful, what kinds of cooperation would be preferable, and whether other key countries are likely to agree to measures that will produce the desired results. Three strategic objectives represent a core of continuity in U.S. national space policy over time, despite major disagreements about what they mean in practice and how they should be pursued: (1) to secure the space domain for peaceful use; (2) to protect space assets from all hazards; and (3) to derive maximum value from space for security, economic, civil, and environmental ends.

This paper analyzes the three strategic logics for space cooperation evoked by different policy ideas being used in the Obama Administration's space and security policies. The Global Commons logic seeks more informal cooperation so that a multitude of self-interested space users can share a "congested" environment without causing unintentional harm. In the Strategic Stability logic, U.S. use of space is increasingly "contested” by states or non-state actors who might attack vulnerable space assets to offset U.S. military advantages. In this logic, the primary purpose of space cooperation is to minimize such attacks by increasing the negative consequences for attackers, reducing their potential benefits, and avoiding misperceptions. The Space Governance for Global Security logic centers on characterizations of space as "interdependent" and "multifaceted." This logic emphasizes that the more different countries, companies, and individuals depend on space for a growing array of purposes, the more they need equitable rules, shared decision-making procedures, and effective compliance mechanisms to maximize the benefits that they all can gain from space, while minimizing risks from irresponsible space behaviors or deliberate interference with legitimate space activities.

Each logic highlights important features of the evolving space arena, and each gives good reasons why greater international cooperation could help accomplish U.S. objectives at an acceptable level of risks and costs. Since the main goal of U.S. space policy in recent years has been to maximize U.S. military power and freedom of action in space, with commercial and civilian interests subordinated to that goal, ${ }^{6}$ most Americans and allies who argue for greater space cooperation use the Global Commons or Strategic Stability logics. Although the Global Commons logic has the widest appeal, emerging space environmental problems do not seem urgent enough to motivate much more cooperation than has already been achieved since this collective action rationale for cooperation gained adherents in the 1990s. Framing the case for space cooperation in environmental terms also obscures, and is obstructed by, conflicting security interests among different spacefaring nations. Using the Strategic Stability logic to build the case for more space security cooperation, on the other hand, intensifies the sense of urgency by exaggerating conflicting security interests. In doing so, though, it risks inadvertently stimulating competition, and undermining the prospects for cooperation. 
The Space Governance for Global Security Logic broadens the rationale for cooperation to include the mutual positive gains that space users can achieve at lower cost through collaboration, as well as the negative benefits from reducing risks of inadvertent interference and deliberate attack. It offers a more compelling reason to increase policy coordination than the Global Commons logic does, and a more constructive context for space security cooperation than the Strategic Stability logic. Although the Space Governance for Global Security logic might encounter more initial political resistance in the United States than the other two logics, it is more likely to produce international agreements that accomplish the desired results. Domestic political resistance could be overcome by showing how space has become integral not only to modern U.S. military operations, but to all the major elements of the 2010 National Security Strategy's vision for promoting security, prosperity, and shared values by building a just and sustainable international order in space as well as on Earth.

\section{Sustainable Management of Space as a Global Commons}

Domains, such as space, the high seas, the atmosphere, and Antarctica, that are considered "global commons" lie beyond the sovereign jurisdiction of any state, are governed by international law, and are available for all to use for the common good. This creates a right of access that does not exist for land, territorial waters, or airspace under a sovereign government's control, at the same time that it strengthens the responsibility to respect other states' interests.

The 1967 Outer Space Treaty (OST) provides the basic legal framework for managing space as a global commons. It designates space as the "province of all mankind."7 It cannot be appropriated (Article II), but can be freely accessed "without discrimination of any kind," and "on a basis of equality." The exploration and use of space should be "for the benefit ...of all countries, irrespective of their degree of economic or scientific development" (Article I), and must be "in accordance with international law... and in the interests of maintaining international peace and security" (Article III). The OST further specifies that States Parties shall conduct space activities "with due regard to the corresponding interests of all other States Parties." They shall consult before doing anything that might cause harmful interference for other space users (Article IX), shall be liable for damage caused to others (Article VII), and shall help each other's astronauts in emergencies (Article V). Neither the OST, nor any subsequent space law, though, provides detailed rules or an authoritative process for deciding what types of space activities are inconsistent with these principles, when the individual or cumulative usage of space might damage the common interests, and how the benefits from space activities should be shared.

For collective action theorists, the global commons characteristic of space evokes Garrett Hardin's "tragedy of the commons," a class of coordination problems that arise when many short-sighted, self-interested users try to maximize their own gains from consuming a nonexcludable public good without regard for the net negative effects on other users, on finite resources, on the shared environment, and even on their own long-term benefits. ${ }^{8}$ As the commons becomes overcrowded and degraded, users must consume more just to get the same level of benefit, so a downward spiral begins that individual users are powerless to stop. Averting tragedy involves either the establishment of a central authority to make rules, verify 
compliance, and respond to violations, or less formal self-regulation by enough users to ensure sustainability. Voluntary norms, transparency measures, and peer pressure can produce sustainable behavior if the users value their social relationships as much as they value their shortterm material gains from over-using or abusing the commons; if all users can be educated to understand that mutual restraint is essential to preserving their livelihood over time; or, if the common environment can tolerate a moderate amount of bad behavior without breaking down. Clear legal rules, effective verification, and well-resourced implementing organizations become more important when a weak sense of community leaves the users focused primarily on their own short-term cost-benefit calculations, when the sustainability of the global commons is under more serious threat, and when high rates of compliance are needed to protect it. ${ }^{9}$

Despite the vastness of space, certain kinds of crowding and irresponsible use are already raising the risks that individual space users will inadvertently cause problems for each other. The two most commonly cited examples involve allocating orbital slots and radio-frequency (RF) spectrum so that one satellite's transmissions do not interfere with a neighboring satellite's operations, and minimizing orbital debris that could damage satellites or space vehicles. Because the most powerful actors would currently rather keep negotiation and implementation costs low and preserve flexibility than obtain high rates of compliance with effective and equitable rules, they have preferred relatively weak international coordination and self-governance mechanisms. But the inadequacies of this approach are apparent in both areas, and will likely get worse as the number and diversity of space users continues to grow, each wanting more from space and each able to have a greater impact, for better or for worse, on others' space usage.

Overcrowding is most severe in geostationary orbit (GEO), where satellites need substantial orbital separation so that the high-powered signals required to reach Earth do not interfere with neighboring satellites. Only a small number of satellites can fit in the equatorial arcs over the United States and other prime geographic locations. ${ }^{10}$ Resource constraints and interference problems are not increasing proportionally to satellite population growth because technological advances are enabling satellites to operate in closer proximity, use RF spectrum more efficiently, and coordinate movements to avoid affecting neighboring satellites. Still, the International Telecommunications Union (ITU) system for coordinating orbital slots and spectrum usage needs ongoing improvement to process registration applications more efficiently, reduce "paper satellites" (slots registered to non-existent satellites), and increase compliance with registrations and technical recommendations. As more new countries and companies gain the technological capability and financial resources to put satellites in GEO, pressure will mount to revisit a system that still allocates scarce orbital slots foremost on a "first come, first served" basis, more or less in perpetuity. ${ }^{11}$

In addition to 1,100 active satellites, space is also littered with debris and defunct satellites, spent rocket stages, explosion or collision fragments, paint flecks, and other human-made objects that serve no useful purpose. The United States currently tracks more than 19,000 objects that are 10 centimeters $(\mathrm{cm})$ or larger, and experts estimate that there are another 300,000 objects in the 1 to $10 \mathrm{~cm}$ range, each able to cause serious damage if it collides with a satellite at orbital speeds, plus millions or billions of very small objects that could degrade satellites or damage certain sensors and subsystems. ${ }^{12}$ 
While collisions between space objects have been rare, several recent hits and near misses have increased awareness of the operational risks and complications caused by space debris. ${ }^{13}$ Of greatest concern is the possibility that a cascade of collisions-a series of hits creating ever larger numbers of debris and greater collision probabilities_could make some "valuable orbital regions increasingly inhospitable to space operations over the next few decades."14

Spacefaring countries have made gradual progress on debris mitigation. Beginning in the 1990s, the United States, the European Space Agency (ESA), and other spacefaring countries developed national guidelines to reduce the production of debris during launch and on-orbit operations, to move GEO satellites into graveyard orbits at the end of their service life, and to put defunct low Earth orbit (LEO) satellites into 25-year decay orbits. Following such best practices involves additional costs, complicates operations, and shortens the useful life of satellites. Therefore, national requirements, compliance, and enforcement levels vary. Some space-users, including China, still do not have national debris mitigation guidelines.

To harmonize and strengthen national practices, the United Nations Committee on Peaceful Uses of Outer Space (UNCOPOUS) asked the Inter-Agency Space Debris Coordination Committee (IADC) to develop international guidelines that were adopted by COPUOS in 2007 and endorsed by the UN General Assembly. The vague language still lets each space user and state decide how many design and operational changes are reasonable to limit debris production, minimize breakup potential, reduce the probability of accidental collision, and avoid intentional destruction, especially in ways that produce long-lived debris. Since compliance with the guidelines is voluntary, it also remains weak. For example, only 11 of 21 GEO spacecraft that ended their service life in 2009 were disposed of properly. ${ }^{15}$

The European Union (EU) has a parallel effort to promote responsible use of the space commons through a Code of Conduct for Outer Space Activities. The code mainly reiterates principles that spacefaring countries have already endorsed in the OST and elsewhere, without adding greater clarity or new mechanisms to decide how those principles should be applied in controversial cases. The most significant additional behavioral guideline admonishes signatories to avoid actions that generate long-lasting space debris and those that otherwise damage or destroy space objects, unless done to reduce space debris or address imperative safety considerations. Such a norm might inhibit behavior driven by economic or prestige motivations, but security concerns would probably override environmental considerations. Furthermore, this way of defining "responsible" behavior stigmatizes the 2007 Chinese ASAT test, but not the United States use of a sea-based ballistic missile interceptor to destroy the malfunctioning USA 193 spy satellite on the implausible grounds that its fuel tank might present a human health hazard, an action that most neutral observers believe had a different, but equally negative, effect on space security. ${ }^{16}$ Proponents will have a better chance of establishing new norms in space that reduce debris production and other irresponsible behavior if the rules are fair, if others exercise comparable restraint, and if the social disapproval campaign is coupled with positive efforts to address the underlying reasons why states might be tempted to pollute the space environment.

As the space global commons becomes more congested, having fuller and more accurate information about the location and projected movements of space objects can help satellite operators know when the probability of a collision is high enough that scarce fuel should be 
expended to move out of harm's way. Space surveillance information can also be used to monitor space population growth and raise awareness about the need for more collective action to protect the space environment. The Obama Administration has made improving U.S. space situational awareness (SSA) a major priority; its budget proposal for 2011 increases spending on relevant programs by roughly 70 percent over the previous year. ${ }^{17}$ The rate of increase in cooperation in collecting, analyzing, and disseminating space surveillance information, though, has been much lower.

The United States military owns and operates the most extensive network of optical and radar sensors, and has the most complete catalogue of space objects, but its space surveillance network (SSN) has limitations. It can generally only keep track of objects greater than $10 \mathrm{~cm}$ in diameter, has had no sensors in the southern hemisphere, has very limited deep-space tracking capability, and, until recently, only had enough analytical resources to watch for potential collisions involving human spaceflight missions, critical U.S. government spacecraft, and certain other satellites of interest. The public catalogue does not include many thousands of objects that the United States military is tracking, nor is the public data accurate enough to be useful for collision avoidance decisions. Commercial and foreign spacecraft operators can request more detailed information, but reviewing and processing their request can preclude timely answers. Other countries have some independent ability to collect additional space surveillance information that they can use alone or in conjunction with data from the public SSN catalogue, but none can duplicate the basic features of the SSN. ${ }^{18}$

Since the 2007 Chinese ASAT test and the 2009 Cosmos-Iridium collision, the United States has taken steps to improve its own SSA, and to share more information with other space actors. It is adding new sensors to the SSN, such as a space-based surveillance satellite launched in September 2010 into a polar orbit from which it can scan all of GEO once a day. The Joint Space Operations Center of the United States Air Force has increased its analytical capabilities enough to do regular conjunction analyses for all active satellites against all objects in the catalogue. It has legal agreements to facilitate data sharing with 16 commercial entities, and is also exploring ways to better share space surveillance data and costs with friends and allies, starting with Europe. ${ }^{19}$ The United States military remains reluctant to share comparable information on a regular basis with countries that are not close friends.

In sum, there are good reasons for conceptualizing space cooperation as managing a global commons so that a growing number of individual space actors can continue to use it in a safe, equitable, and sustainable manner, but there are also major reasons why framing the need for greater space cooperation in this way is unlikely to produce international agreements that make a major difference in outcomes. Interference from overcrowding and accidents caused by space debris have so far been low probability, low consequence events. This makes it hard to convince policy makers outside of the space community that they should devote significant time, money, and political capital to get more rapid international agreement on, and more widespread compliance with, stricter rules, wider information sharing, and better managerial processes. With ongoing wars and the global economic crisis, a 1-in-1,000 chance of a given satellite colliding with a chunk of space debris during a ten-year functional lifetime does not sound too bad. ${ }^{20}$ Debris cascades could dramatically increase the future risks and costs of space operations, but 
that would still pale by comparison with the consequences of global warming or rampant nuclear proliferation.

If proponents of greater space cooperation truly believe that collective action problems like debris mitigation are the most important reason for cooperation, and if they are satisfied with the rate of progress on improving launch, operation, and disposal practices that has occurred over the past fifteen years, then continuing to frame the case for cooperation in these terms is a fine strategic choice. But if they believe that progress towards sustainability in managing space as a global commons has been inadequate, then they need to reconsider the preference for informal self-regulation over more formal and fully developed regulatory arrangements. And if they were hoping to use major successes in relatively uncontroversial types of technical space coordination as a way to build momentum for more significant cooperation on politically difficult space security issues, then they should think about how those larger, more politically sensitive issues are impeding low-priority technical coordination.

Strategic sensitivities impede cooperation because many people whose decisions affect space, especially from U.S. and foreign defense policy communities, resist doing what would make sense for the long-term sustainable management of space as a global commons because they do not think about space in the same way that environmentalists, international lawyers, or collective action theorists do. People who believe that access to and use of space can be controlled for strategic gains relative to potential competitors sometimes invoke the "space as a global commons" phrase as a way to assert their own right to use space without interference from others without acknowledging that other users have similar rights, and that all rights in space confer corresponding responsibilities. An extreme form of this view argues that the United States should become a space hegemon to police the shared environment, protect peaceful uses, and prevent anyone else from accessing or using space for hostile purposes. ${ }^{21}$ Less extreme forms of adversarial thinking also impede functional cooperation by limiting willingness to share space surveillance information and restricting exports of technologies that could help with debris mitigation, space traffic management, and the optimization of scarce resources. The more such adversarial logic dominates decisions about space, the less likely U.S. or foreign decision-makers will be to forego short-term gains and future flexibility in order to protect space from environmental degradation and to avoid social disapproval.

\section{Marginal Space cooperation to Enhance Strategic Stability}

When space is seen in terms of military competition rather than environmental management, the logic for cooperation changes. Instead of assuming that players want to maximize their own absolute gains without regard to others, the starting assumption is that players want to maximize their relative power, even when that reduces their absolute gains or increases operational risks. The impetus for strategic cooperation, as conceived by early arms control theorists, such as Thomas Schelling and Morton Halperin, comes from the one shared interest that potential adversaries have: avoiding mutual disaster. ${ }^{22}$ Competitors can use formal or informal cooperation at the margins of their relationship to stabilize strategic stability by ensuring that nobody believes they could gain more than they would lose by initiating an unprovoked attack; and by reducing 
misperceptions, false alarms of impending attack, command and control failures, and other problems that could cause a nuclear war that neither side wanted.

Space was one of the first arenas where the United States sought limited cooperation with the Soviet Union to enhance terrestrial deterrence stability. The United States wanted space designated as a global commons so that sending remote sensing satellites over Soviet territory would be tolerated in a way that spy planes were not. Satellite over-flights were accepted as peaceful, permissible, and thus, implicitly protected under the OST in the belief that imagery and communications from space were reducing the likelihood of war. Satellites were a non-intrusive way to get information about the superpower military balance and compliance with arms accords. They could provide early warning of actual attacks and calm unwarranted fears. They could also provide superpower leaders with better information and direct communication for crisis management and escalation control.

In space law, very few national security activities have been explicitly prohibited (e.g. weapons of mass destruction in orbit and military uses of celestial bodies) or protected (e.g. satellites used to verify treaty compliance and for the crisis "hotline.”) Still, the superpowers tacitly tolerated each other's use of space in stabilizing ways and practiced reciprocal restraint regarding destabilizing activities. Neither vigorously pursued dedicated ASAT options, nor put conventional weapons in space that could be used for pre-emptive attacks on strategic targets, although both engaged in some exploratory ASAT work as a hedge, and both had other latent retaliatory options if their satellite were attacked. Even after the Soviets conducted a series of dedicated ASAT tests during the Nixon Administration, the United States decided not to intensify its own ASAT development because this would be less likely to enhance deterrence of Soviet ASAT use than to stimulate an ASAT arms race that would disproportionately hurt the United States. ${ }^{23}$ As doubts about Soviet commitment to détente and deterrence stability grew, though, U.S. interest in reciprocal ASAT restraint declined. It disappeared altogether once the Reagan Administration decided that the most reliable way to increase terrestrial deterrence stability was to use space to enhance U.S. high-technology war-fighting advantages that could prevent the Soviets from thinking that they could gain more than they would lose by starting a nuclear war.

Many analysts who currently favor limited space arms control to enhance strategic stability formed their security logic during the Cold War, and are adapting it to changed strategic circumstances. Instead of two superpowers with roughly equal nuclear, conventional, and space capabilities trying to compete for advantage without causing a nuclear war, now the central challenge from a U.S. perspective is to keep weaker players from being able to offset U.S. strategic advantages by threatening or using asymmetrical attacks against the space assets on which U.S. military power and economic prosperity disproportionately depend. Since it is unrealistic to expect that the United States could gain the level of comprehensive space dominance needed to physically preclude other countries from interfering with U.S. space operations, some U.S. strategists argue that the best way to avoid such attacks would be to persuade potential aggressors that any benefits from interference would be outweighed by the expected costs. 
This is often called "space deterrence," but the analogy with nuclear weapons is highly misleading. A more accurate and less pejorative term would be "space dissuasion," because retaliatory threats against space or terrestrial targets would be of low credibility and limited utility compared with other ways of changing cost-benefit calculations. The most thoughtful studies emphasize dissuasion strategies that would be relatively non-threatening, such as making satellites less attractive targets, raising the political and legal costs of ASAT attacks, and underscoring that even limited interference with satellites could lead to mutual disaster by sparking a catastrophic collapse of global financial markets, for example, or causing a low-level conflict to escalate out of control. ${ }^{24}$ Even these studies, however, recommend that the United States develop some defensive capabilities that could also have offensive applications, increasing the likelihood that other space actors will seek to emulate or offset such U.S. strategic choices in ways that stimulate a downward spiral of weapons acquisition, tensions, and possible preemptive action in a crisis or a war.

Whereas Americans fear asymmetrical attacks on their superior space assets, the Russians and Chinese worry that U.S. space and missile defense advantages will cause the United States to be less cautious in regional crises that affect their interests. ${ }^{25}$ To draw global attention in the late 1990s to these destabilizing effects of U.S. missile defense and space ambitions, the Russians and Chinese became increasingly vocal proponents for negotiating on "Prevention of an Arms Race in Outer Space” (PAROS) in the Conference on Disarmament (CD). This agenda item gained near universal support in annual UN General Assembly resolutions, but the United States vehemently objected that there was no Cold War-style arms race occurring in space, so no additional measures were needed.

In 2008, Russia and China introduced a draft treaty that would extend the OST's ban on WMD in space to prohibit placing all types of orbiting weapons there. It would also explicitly ban the threat or use of all types of force against space objects. ${ }^{26}$ Their "Prevention of the Placement of Weapons" (PPW) proposal has been widely dismissed as a propaganda ploy, in part because it would outlaw U.S. deployment of space-based missile defense interceptors (the main Russian and Chinese goal), but not prohibit debris-generating ASAT tests or prevent the proliferation of ASAT capabilities, the most important arms control objectives for other spacefaring states. The Bush Administration also objected that the dual-use nature of much space technology would make it impossible to define and verify a ban on space weapons without impeding the peaceful

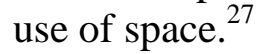

U.S. proposals for cooperative steps to improve strategic stability in space have eschewed broad legal limits on capabilities in favor of dialogue and transparency and confidence-building measures (TCBMs). The Obama Administration has been trying to establish regular bilateral strategic stability talks with Russia and China covering nuclear, space, and cyber-security issues. The United States has also been calling on China, in particular, to be more transparent about its space programs, capabilities, and intentions. While the administration says that strategic dialogue would provide "mutual reassurance in the space domain," its public remarks highlight advances in Chinese counterspace capabilities that concern the United States without acknowledging that the United States already has more advanced counterspace capabilities of great concern to China. $^{28}$ 
Americans and Europeans often propose transparency measures as a low-risk way to test intentions and dispel misperceptions that could generate unwarranted suspicions, arms build-ups, and fears of attack. Other countries have a less favorable view of transparency for its own sake. While Russia and China have agreed to extensive and intrusive verification when necessary for high confidence in compliance with legally binding arms control treaties that serve their security interests, they have usually rejected requests to provide sensitive information without a legal agreement regulating its provision and use. That reluctance is partly cultural, but it is also strategic; the weaker player has greater reason to worry about sharing information that might reveal their vulnerabilities, especially in the absence of any constraints on the stronger player's capabilities or actions. The United States probably also overestimates the reassurance value of minor TCBMs, like presentations on national space policies and expert visits to military satellite flight control centers, given the huge gap between U.S. military space capabilities and those of all other countries and the amount of classified information about U.S. military space spending, programs, and capabilities that would undoubtedly be excluded from these interactions. Despite such reservations, Russia has for several years sponsored a UN General Assembly Resolution calling upon states to propose outer space TCBMs "as a means conducive to... the prevention of an arms race in outer space.” Although all members of the EU co-sponsored this resolution in 2009, the Obama Administration abstained because, at the time, it had not yet completed its space policy review.

This review included a "blank slate analysis of the feasibility and desirability of options for effectively verifiable arms control measures that enhance the national security interests of the United States and its allies." 29 A "blank slate” implies that reviewers were directed to reconsider the anti-arms control principle added to the 2006 National Space Policy that the United States will categorically oppose "the development of new legal regimes, or other restrictions, that seek to prohibit or limit U.S. access to, or use of, space."30 But long before the review was completed, participants had already announced that the United States will continue to "reject any limitations on the fundamental right of the United States to operate in, and acquire data from, space."31 This sounds like a softer way of shutting off serious internal debate or international discussion about the net security effects of accepting new legal limits on U.S. freedom of action in order to get stronger legal protections for legitimate satellites and corresponding restrictions on other countries' capabilities or actions that could threaten U.S. access to or use of space. ${ }^{32}$ The 2010 National Space Policy does express a willingness to consider arms control proposals if they are equitable, effectively verifiable, and beneficial for national security, but it does not indicate that the United States should take any initiative to develop proposals fitting these criteria. And while the criteria sound reasonable, the formula also risks prematurely ruling out exploration of possible agreements that might not be fully verifiable, but that could nevertheless enhance the net security interests of the United States and its allies. ${ }^{33}$

If the Obama administration did decide to propose some type of legally binding space arms control measure, the most likely option would be a stand-alone ban on kinetic energy ASAT tests. This idea was endorsed by a Council on Foreign Relations task force on U.S. nuclear weapons policy that included several current high-level DOD officials involved in the Obama Administration's space policy reviews. ${ }^{34}$ Because of the indiscriminate risks that ASATgenerated debris pose to military, intelligence, and commercial satellites, the United States has invested heavily in non-destructive means of temporarily disabling or permanently destroying 
satellites performing hostile functions. Since it already has effective kinetic energy ASAT capabilities that could be used if other means would not suffice, the United States would give up little and gain a lot from a kinetic energy ASAT testing ban that prevented other countries from refining or acquiring this capability and protected the space environment at the same time. But proposing a stand-alone kinetic energy ASAT test ban would look just as self-serving as the PPW proposal does, in that it would provide additional protection for space objects, the main U.S. concern, but no new protections against space weapons, the main Russian and Chinese concern.

If the United States wants to pursue a kinetic energy ASAT ban in a way that does not look like a propaganda ploy, then it needs a more balanced proposal that combines constraints on ASAT testing with measures to reduce motives for acquiring or using those weapons. Alexei Arbatov, a leading Russian arms control and security expert, has proposed a trilateral ban on testing ASATs and space-based missile defense interceptors as a practical, equitable, and verifiable form of limited space arms control. ${ }^{35}$ A more ambitious approach could build on an idea advanced by Canada to couple a voluntary or legally binding rule against weapons in space with a comparable rule against testing or using anything as a destructive ASAT, including another satellite. ${ }^{36}$

Those who want greater strategic stability in space want better space surveillance capabilities for reasons beyond debris mitigation, collision avoidance, and efficient sharing of scare resources. If the central U.S. objective is to deter deliberate interference with U.S. space systems, then potential attackers must be convinced that the United States will know who to punish for interference, something that would be much more difficult to do in space than with a nuclear attack. ${ }^{37}$ Potential attackers might also be dissuaded if they knew that the United States would have enough warning to move a satellite out of harm's way or take other protective actions to deny benefits from an attack. Improved space surveillance could help avoid crises and possible space conflicts that might arise if one state falsely accused another of attacking its satellite when the problem had actually been caused by an internal malfunction, a natural hazard, a piece of space debris, or a different space actor. It could also be used to verify compliance with space arms control agreements, such as a ban on testing or using destructive ASATs, or a rule requiring satellites to keep a specific distance away from each other, unless they had permission to conduct close proximity operations.

The more emphasis that is placed on dissuading aggressive attacks, the more the United States will want superior SSA relative to potential attackers. But restricting routine SSA sharing to close friends and allies would drive a wedge between the "in group" and excluded countries, damaging relationships, generating suspicions, and reducing the amount of SSA information available for anyone to use for non-adversarial purposes. The more space stability is seen as a defensive security dilemma, the more interest the United States should have in sharing space surveillance information to reduce unwarranted fears, resolve ambiguities that could produce false alarms, minimize mutual incentives to acquire more destabilizing military space capabilities, and monitor compliance with cooperative accords.

When applying the Strategic Stability logic to space, most U.S. defense analysts are missing the biggest reason why the United States should be willing to go beyond dialogue, transparency, and voluntary norms to stronger, more reliable forms of security cooperation-the connection to 
nuclear weapons and terrestrial strategic stability. DOD officials engaged in the space policy reviews have said that the main reason why the Soviets never attacked U.S. satellites was because they believed that would lead to a nuclear war. These officials assume that adversaries will be less inhibited now because the United States would probably respond to most kinds of space interference with non-military or conventional means. In other words, increased nuclear strategic stability has decreased space strategic stability.

Russian and Chinese arms control experts see a very different relationship between nuclear and space capabilities as they affect overall strategic stability. They argue that because the new U.S. strategic triad includes not only nuclear weapons, but also space-enabled precision conventional strike weapons and missile defense, it will be impossible to preserve strategic stability at progressively lower levels of nuclear weapons without addressing U.S. space and missile defense programs that Russia and China deem most threatening. Russian officials have repeatedly indicated that any follow-on negotiations to the new strategic arms reduction treaty signed in April 2010 (New START) must include some reliable reassurance that the Obama Administration's "phased adaptive” global missile defense program will not evolve to undermine Russia's nuclear deterrent, and that the West's conventional precision strike capabilities will not require Russia to keep large numbers of tactical nuclear weapons. Since China's nuclear stockpile still has fewer than fifty long-range weapons, it has even more need than Russia does for reassurance about U.S. missile defense and space capabilities and intentions before it will contemplate new constraints on, or reductions in, its nuclear arsenal.

While space cooperation can make valuable contributions to strategic stability, it would be a mistake to use an adapted version of Cold War deterrence and arms control logic as the dominant way to conceptualize it. ${ }^{38}$ That logic assumed a fundamentally adversarial bilateral relationship, where the prime indicators of relative power (nuclear weapons and conventional forces) could be directly compared, and the only common interest lay in avoiding mutual nuclear disaster. None of those conditions hold in space. There, a growing number of states and non-state actors interact in complicated patterns using ambiguous systems that can have both military and non-military applications. Moreover, compatible interests have always been far more common in space than antagonistic ones. Making deterrence the dominant paradigm for space security would not only perpetuate Cold War-style nuclear relationships among the United States, Russia, and China, it would also unnecessarily recreate the same dangerous dynamic in space, where it would be much more difficult to avoid deliberate or inadvertent deterrence failures. At the same time, it would raise the costs of using space for commercial and civilian purposes, and impede the close cooperation that the United States needs from Russia, China, and a number of other spacefaring countries if it wants to achieve its highest priority objectives for security, prosperity, and world order. Therefore, while the United States should pursue cooperative steps that would increase both space and terrestrial strategic stability, it should frame its reasons for seeking space cooperation using a less adversarial, more ambitious, and more inclusive rationale.

\section{Space Governance for Global Security}

The Global Commons logic and the Strategic Stability logic are inadequate conceptual frameworks for producing international agreement and compliance with cooperative measures to 
advance U.S. objectives in space because their rationales for cooperation are framed in narrow, negative terms: further minimizing risks of inadvertent interference and deliberate attacks on space assets. One way to gain more from space cooperation, more quickly and with less risk of a downward spiral, would be to frame the objectives of cooperation broadly, in both positive and negative terms, as Space Governance for Global Security.

International relations theorists use the term "global governance" to describe institutional arrangements developed by sovereign state and non-state actors to do for the world what wellfunctioning domestic governments do for their own citizens, but without establishing a world government with the power and authority to make and enforce rules, collect taxes, and allocate resources. Domestic governments provide protection against external and internal threats; public goods and services that private actors need to function and flourish, but cannot do effectively or efficiently on their own; and collective decision-making processes that members accept as legitimate. Strategies to promote global governance in a given issue area aim to approximate some or all of these functions by building on the existing patchwork of treaties, norms, diplomatic forums, intergovernmental organizations, market relationships, and transborder civil society networks. They aim to develop progressively more comprehensive and coherent arrangements to address shared problems more efficiently, effectively, and equitably than existing cooperative institutions can. ${ }^{39}$ Instead of assessing negotiation, verification, and compliance management only as "transaction costs" that participants will want to shirk or minimize, this logic also treats them as investments in building the knowledge, relationships, rules, monitoring capabilities, and joint decision-making mechanisms needed to support increasingly ambitious forms of cooperation.

The "Space Governance for Global Security" logic starts from the premise that all current and future space users share the same strategic objectives attributed to the United States: to secure the space domain for peaceful use; to protect space assets from all hazards; and to derive maximum value from space for security, economic, civil, and environmental ends. If the goal of space cooperation is to maximize all participants' interests in these shared objectives, then the benefits of cooperation become much larger and more compelling than in the other two logics. Modern space operations are much more expensive and technologically challenging than grazing cattle, and the diversity of interests and capabilities among space users is much greater than among the villagers sharing Hardin's commons. Therefore, space cooperation should have the positive objective of organizing space users to work together and accomplish more for less than they could on their own, not just the negative objectives of minimizing inadvertent interference, environmental degradation, or deliberate attack.

The United States space community has long understood the importance of having an inspirational vision to mobilize and sustain the high levels of public support and private investment needed for major space accomplishments. ${ }^{40}$ Instead of trumping up a new space race with China, or setting a multi-decade goal of going to a new planet in hopes of gaining unspecified insights into existential questions, technology and education spin-offs, and national prestige, it would be more realistic and compelling to frame a positive vision around using space cooperation to address urgent current terrestrial challenges. The 1999 Vienna Declaration on Space and Human Development highlighted how greater international cooperation and investment in space technologies could be leveraged to promote sustainable development, spread 
the benefits of global communications, enhance natural disasters response, and improve health care and education in underserved regions. ${ }^{41}$ But, progress on this agenda has been slow because the countries with the most space assets and investment resources do not see such development projects as having a significant impact on their own well-being. A more persuasive case for space cooperation would be framed in terms of the positive contributions it could make to promote the security, prosperity, and values of the United States and of the other countries whose support will be essential for success.

The 2010 National Security Strategy makes passing references to U.S. dependence on space systems that are vulnerable to disruption and attack, and to the need for strong multilateral cooperation to safeguard and optimize the use of space as a global commons. Space cooperation could be used more ambitiously in the overall strategy if it were conceived as a leading opportunity to build the global governance institutions needed to accomplish that strategy's goal of creating a "just and sustainable international order that can foster collective action to confront common challenges." 42

The central strategic challenge facing the United States is that the very elements on which its security, prosperity, and way of life depend-rapid technological innovation; a tightly interconnected global economy; and the free flow of people, goods, services, and ideas across borders-also increase its vulnerabilities both to deliberate attack and to unintentional dangers, such as a collapse in financial markets, pandemic disease, or climate change. To promote the positive aspects of globalization, while minimizing the risks, the National Security Strategy calls for using all elements of U.S. power to build a "rules-based international system that can advance our own interests by serving mutual interests." As the most powerful player in the system, the United States wants rules to provide reassurance that weaker players will not exploit its vulnerabilities for asymmetrical attacks, that developing countries will behave responsibly rather than cut corners and cause problems for others, and that rising powers will want to join rather than change the status quo. But for this rule-based order to attract widespread support and sustained compliance, the United States must also provide credible reassurance that it will follow the rules itself, that it will not use its military and technological advantages in ways that harm others' interests, and that it will support international governance arrangements that give others a meaningful voice in decisions that affect their security, prosperity, and way of life.

Space epitomizes these current strategic challenges. It serves functions of vital importance for high-technology military operations, electronic financial transactions, power-grid operations, and countless other aspects of life in the information age. Yet, the space technologies needed for these beneficial purposes can also be deliberately or inadvertently misused in ways that threaten inherently vulnerable satellites and those who depend on them. Space is central to U.S. military, economic, and technological predominance; it matters greatly to countries who aspire to interact as equals with the United States; and it offers hope to those who have not yet benefitted much from globalization. Thus, there are both practical and symbolic reasons to choose space cooperation as a leading opportunity to provide mutual reassurance and to build effective global governance institutions.

The drafters of the OST could see the outlines of this challenge half a century ago, even if they could not anticipate the details, so the treaty already includes the basic principles needed for 
equitable and effective space governance. One reason why the George W. Bush Administration's space policy raised foreign concerns was that a military competition to control space for U.S. national advantage would contradict these basic principles. The Obama Administration has reaffirmed general U.S. support for the OST principles, but should be more specific about how it interprets those principles in light of recent controversies. It would be more reassuring, for example, if the United States explicitly declared that stationing weapons in space would be inconsistent with Article III's directive that space be used for peaceful purposes, and that any type of interference with satellites operating in a manner consistent with the OST's peaceful purpose clause would violate Article I's equal access principle. If other spacefaring nations made parallel unilateral declarations, it would quickly reinforce existing legal commitments and longstanding norms against space weapons and ASAT attacks. U.S. willingness to begin negotiations on a companion document to the OST giving these norms full legal force and addressing more controversial questions about when the use of space for terrestrial warfighting should be protected or prohibited would provide powerful evidence that the United States is willing to accept mutually beneficial constraints, even in an area where it has a relative advantage.

The OST and associated accords lack formal institutional mechanisms to promote international cooperation in the peaceful uses of space, to monitor compliance and resolve compliance problems, and to make collective decisions about the application of space rules in ambiguous or novel situations. There are international bodies that do, or could, discuss, negotiate, and/or implement different aspects of space cooperation. But all of these entities are weak, each focuses only on a subset of space issues, and there is little coordination or communication among them. Insisting that COPUOS concentrate on the peaceful uses of space and that military space issues only be dealt with by the CD makes no sense when the same technologies, and often the same satellites, can have both non-military and military functions, and when commercial or civilian satellites are more vulnerable to deliberate interference or ASAT debris than hardened military satellites are. Rules and decision-making processes designed when only a few governments could build and launch satellites for their own purposes must also be adapted for an era in which more than fifty countries have launched satellites on their own or in collaboration with others, and commercial space revenues have outpaced governmental space spending. Approaching space cooperation not in an ad-hoc, issue-specific way, but through a comprehensive process to improve overall space governance for global security, would direct attention towards developing decision-making and implementation bodies that have the mandate, legal authority, and resources needed both to expand space cooperation in their own domain, and to coordinate more effectively across space issue areas.

Many types of space cooperation advocated as measures to protect the global commons or enhance strategic stability would receive greater international support if they were pursued as part of a broader Space Governance for Global Security strategy. Users would be more inclined to protect the space environment if collaborative projects increased stakeholders' net benefits from space, and strengthened their sensitivity to social norms. If voluntary self-regulation was deemed inadequate, it would be much easier to get international agreement outlawing destructive ASAT operations and other activities that pose high risk to the space environment if this was coupled with correspondingly strong rules addressing related aspects of space security. Efforts to improve space surveillance could be more comprehensive, at less cost to the United States, and 
with less concern that the information might be misused for military advantage, if all spacefaring countries and satellite operators contributed on an equitable basis to establish a geographically distributed network of sensors feeding into an international data center responsible both for providing space users with information needed for safe, efficient operations, and for monitoring compliance with space security accords.

On the surface, this way of framing the logic for space cooperation sounds radically idealistic compared to recent U.S. policy and to the minimalist forms of space security cooperation that most American analysts currently consider politically viable. But, it would be directly in line with the OST principles that the United States initially championed as the most reliable way to protect and promote those uses of space deemed most important to U.S. security. A return to robust reciprocal restraint followed by a concerted effort to negotiate stronger legal protections for satellites and prohibitions on the testing or deployment of ASAT weapons would enjoy strong public approval in the United States, and even greater support in other countries. ${ }^{43}$ Building a strategy for space governance around the three shared objectives identified above would be consistent with the proclaimed orientation of every space power. It would also hold great appeal for the countless state and non-state actors who want benefits from space, but do not have their own space programs, and thus, have very little power over space developments that affect their lives.

On deeper reflection, there are good reasons to believe that if it made a concerted effort, the Obama Administration could generate widespread support among different segments of the space community for a policy that better balanced commercial, civilian, and military interests, and that used international cooperation both to share the costs and benefits of peaceful space operations, and to reduce all hazards to space systems. The commercial and civilian space communities would certainly endorse these goals, although private space actors would resist regulations if they were unnecessarily top-down, and would want to join governmental representatives in making decisions that directly affected their commercial space operations. Even most of the military might support this reframing because they care more about preserving U.S. access to space for terrestrial military support and intelligence purposes than they do about denying other countries access to space or putting weapons there.

The United States military would have to foreclose some options and give up some freedom of action in space in return for stronger legal protections for permitted uses of space and reciprocal restraints on what other countries could do there. But much of what the United States would give up would be things that it is highly unlikely to do anyways for technical, economic, and strategic reasons, such as deploying a space-based layer of missile defense interceptors. Therefore, it should reap the political and security benefits from making reassuring commitments. Few U.S. military, space, or security experts regret that the OST ruled out orbiting WMD and putting military bases on the Moon. They would more likely feel relief than regret if a companion agreement precluded anybody from putting terrestrial strike weapons in space for another fifty years. Other things that the United States might be tempted to do now in extreme circumstances, such as disabling an adversary's space-based military communication or satellite-imagery assets at the outset of a war, will appear increasingly undesirable as more states and non-state actors have the technical ability to target space assets upon which the United States more heavily depends. 
Much of what the Obama Administration is trying to do in the commercial and civilian components of its new National Space Policy would fit well with this approach, such as reforming the U.S. export control system so that it is easier to sell non-military satellites and to work with foreigners on the International Space Station (ISS), while also trying to persuade other countries with space technologies that pose a true security risk not to sell or share them with those who might misuse them. In the military side of space policy, the publicly discussed concept that comes closest to this logic is the systematic promotion of "selective interdependence.” This phrase suggests that for certain space applications, such as environmental monitoring or missile warning, the United States could work with other countries to build more capable systems, while sharing the costs and benefits, such that all users would have strong incentives to protect the system and to respond vigorously against anyone who attacked it. The more selective the United States is, though, both in the kinds of space activities where this concept is applied and the number of partners included, the less beneficial it will be. And recognizing the strategic value of selective interdependence is but the first intellectual step towards understanding the kinds of global governance arrangements needed to manage complex interdependence among a multitude of actors and across multiple domains in, and affecting, space.

\section{Conclusion}

The most important step in strategic thinking is correctly defining the structure of the problem to be addressed by cooperation or unilateral action. The Obama Administration has clearly indicated that it wants more international cooperation than its predecessor did, both in space and in its overall national security strategy. But it does not seem to have a clear conception of the kind of cooperation it wants in space, nor a viable strategy for persuading other countries to work with it on measures that would be strong and comprehensive enough to get the desired results. Even as it tries to differentiate itself from Bush-era policies, the Obama Administration still seems conceptually limited to narrow, negative logics for space cooperation that fit within the boundaries of political acceptability during the previous administration. The way to break out of this intellectual box is to think seriously about what it would mean to apply the guiding principles of the 2010 National Security Strategy systematically and comprehensively to global space governance.

Some U.S. strategists will object that no matter how much the United States and the rest of the world might gain in absolute terms by cooperating to secure the space domain for peaceful use, to protect space assets from all hazards, and to derive maximum value from space for security, economic, civil, and environmental ends, the United States should not do anything that would constrain its freedom of action, or reduce the relative advantages that it currently enjoys. This objection is understandable, but outmoded. U.S. asymmetrical advantages in space are matched by asymmetrical vulnerabilities, and the United States cannot unilaterally protect all of its satellites or prevent others from acquiring the means to threaten them, even if it dramatically increased military space spending and ended all space-related exports and civilian cooperation. Mutual vulnerability is an inescapable feature of global security, so promoting widespread 
adherence to equitable rules that regulate behavior, reduce risks, and provide reassurance in space and on Earth is a much more prudent strategic choice than trying to keep all options open.

\section{Notes}

${ }^{1}$ The Obama Administration has undertaken several different, but overlapping, space policy reviews. The National Security Council directed an interagency review of U.S. national space policy, the Department of Defense conducted a congressionally mandated Space Posture Review, and the National Security Space Strategy is being updated to improve coordination between military and intelligence space programs. The National Space Policy was released on 28 June 2010, see National Space Policy of the United States of America, http://www.whitehouse.gov/sites/default/files/national_space_policy_6-28-10.pdf (accessed September 2010). ${ }^{2}$ Deputy Secretary of Defense, William J. Lynn, "Remarks at the National Space Symposium,” 14 April 2010, Colorado Springs, Colorado, http://www.defense.gov/speeches/speech.aspx?speechid=1448 (accessed July 2010). ${ }^{3}$ Remarks by Ambassador Laura E. Kennedy to the UNIDIR Space Security Conference, 29 March 2010, Geneva, Switzerland, http://geneva.usmission.gov/2010/03/29/ambassador-kennedy-space-policy-review (accessed July 2010).

${ }^{4}$ George Jahn, “U.S. agrees to announce missile launches,” Associated Press, 20 May 2010.

${ }^{5}$ The Obama Administration has continued a policy adopted by the Bush Administration in 2007 of agreeing to let the Conference on Disarmament establish an ad-hoc working group to discuss, but not negotiate, cooperative steps to enhance space security. No formal work has occurred on this agenda item, though, because Pakistan has been blocking consensus on a program of work, because it objects to another item on the CD agenda: negotiations on a treaty to prohibit production of new fissile material without reductions in existing stocks (Fissile Material Cutoff Treaty). The most common recommendation to get the $\mathrm{CD}$ functioning again is to relax the interpretation of the consensus rule so that no one country can block negotiations indefinitely, but some countries who want to start the Fissile Material Cutoff Treaty negotiations do not want to relinquish the right to block negotiations on other longstanding topics on the CD's agenda. The United States could expect that other nuclear weapon states, and many nonnuclear allies, would also oppose negotiations on a near-term convention to eliminate nuclear weapons, but it could be the only CD member opposed to starting negotiations about additional legal measures to protect satellites and prevent space weaponization.

${ }^{6}$ This historical sequence is covered in Nancy Gallagher and John Steinbruner, Reconsidering the Rules for Space Security, American Academy of Arts and Sciences, April 2008, http://www.amacad.org/publications/reconsidering.aspx (accessed July 2010).

7J.I. Gabrynowicz, “The 'Province' and 'Heritage' of Mankind Reconsidered: A New Beginning,” The Second Conference on Lunar Bases and Space Activities of the $21^{\text {st }}$ Century, Proceedings from a conference held in Houston, Texas, 5-7 April 1988. Edited by W.W. Mendell, NASA Conference Publication 3166, 1992, p. 691. ${ }^{8}$ The analogy Hardin used to illustrate the need for collective action involved English villagers grazing too many cattle on a common pasture. See Garrett Hardin, "The Tragedy of the Commons," Science, 162 (1968): 1243-1248. ${ }^{9}$ Christopher C. Joyner, "Global Commons: The Oceans, Antarctica, the Atmosphere, and Outer Space,” pp. 354391, in P.J. Simmons and Chantal de Jonge Oudraat, eds., Managing Global Issues (Washington, DC: Carnegie Endowment for International Peace, 2001.)

${ }^{10}$ Jessica West, ed., Space Security 2009, SPACESECURITY.org, p. 40.

${ }^{11}$ See Theresa Hitchens, Future Security in Space (Washington, DC: Center for Defense Information, 2004), pp. 3952; and Gerry Oberst, “Efficient Use of Satellites - Part 2,” Via Satellite, 1 May 2010.

${ }^{12}$ Brian Weeden, “The Numbers Game: What's in Earth’s Orbit and How do We Know?” The Space Review, 13 July 2009, pp. 2-3.

${ }^{13}$ The most noteworthy recent debris-generating events have been the February 2009 collision between an active Iridium communications satellite and a defunct Russian satellite, and China's January 2007 ASAT test. Jessica West, ed., Space Security 2009, pp. 26-33 summarizes debris-generating events and mitigation efforts in the past several decades.

${ }^{14}$ U.S. National Research Council, Orbital Debris: A Technical Assessment (1995), p. 4.

${ }^{15}$ Brian Weeden, "Dealing with Galaxy 15: Zombiesats and on-orbit servicing," The Space Review, 24 May 2010, Part I, p. 8. 
${ }^{16}$ The United States considers the destruction of the USA 193 to be different from the Chinese destruction of its own weather satellite because the United States gave a public health rationale, destroyed the satellite at a lower altitude to minimize persistent space debris, and announced its plans in advance. In other countries' eyes, though, what mattered most about the USA 193 destruction was that it demonstrated how quickly the United States could adapt its missile defense capabilities for an anti-satellite application.

${ }^{17}$ Samuel Black and Victoria Samson, "Space Security Programs of Interest in the Fiscal Year (FY) 2011 Defense Budget Proposal, http://www.stimson.org/space/pdf/Space_Security_Programs_in_FY11_Budget.pdf (accessed July 2010).

${ }^{18}$ Brian Weeden, “The Numbers Game: What's in Earth’s Orbit and How do We Know?” The Space Review, 13 July 2009; and Jessica West, ed., Space Security 2009, pp. 33-35.

${ }^{19}$ Jeff Foust, “A new eye in the sky to keep an eye on the sky,” The Space Review, 10 May 2010.

${ }^{20}$ U.S. National Research Council, Orbital Debris: A Technical Assessment (1995), p. 4.

${ }^{21}$ Everett C. Dolman, Astropolitik (London and Portland, OR: Frank Cass, 2002).

${ }^{22}$ Thomas Schelling and Morton Halperin, Strategy and Arms Control (New York, NY: Twentieth Century Fund, 1961).

${ }^{23}$ Steven Weber and Sidney Drell, “Attempts to Regulate Military Activities in Space,” in Alexander George, et al, eds., U.S.-Soviet Security Cooperation: Achievements, Failures, Lessons (New York and Oxford: Oxford University Press, 1988), pp. 391.

${ }^{24}$ While current U.S. strategists often differentiate between "deterrence by punishment" and "deterrence by denial," only the former fits the historical meaning of the term: using fear to discourage action. This etymology explains why "deterrence" has inherently threatening connotations for Chinese security experts and many others outside the U.S. strategic community. Key differences between nuclear and space deterrence, include the greater difficulty of making threats that are big enough to convince a risk-acceptant aggressor that they will lose more than they will gain through interference with U.S. space systems, but proportionate enough to the original attack to be considered credible by the aggressor. They also include the difficulty of attributing responsibility for an ASAT attack, and problems finding retaliatory options that do not hurt a space-dependent United States more than they hurt a less space-dependent adversary by creating space debris or causing counter-retaliation against more U.S. space assets. On Chinese attitudes toward the term “deterrence," see Gregory Kulacki, “Chinese Intentions in Space,” Space and Defense 4:1 (Winter 2010). On the difficulties of adapting nuclear deterrence to space, see Roger Harrison, et al., "Space Deterrence," Space and Defense 3:1 (Summer 2009): 1-30,

http://web.mac.com/rharrison5/Eisenhower_Center_for_Space_and_Defense_Studies/Space_Deterrence.html (accessed September 2010); and Forrest E. Morgan, Deterrence and First-Strike Stability in Space: A Preliminary Assessment, (Santa Monica, CA: RAND Corporation, 2010).

${ }^{25}$ Alexei Arbatov, "Preventing an Arms Race in Outer Space," in Alexandre Kalliadine and Alexei Arbatov, eds., Russia: Arms Control, Disarmament, and International Security (Moscow: Institute of World Economy and International Relations, 2010), p. 33, http://www.imemo.ru/ru/publ/2010/10003.pdf (accessed July 2010); and Li Bin and Nie Hongzhen, “An Investigation of China-U.S. Strategic Stability,” Gregory Kulacki’s translation of article in Chinese in World Economics \& Politics (2008), http://www.ucsusa.org/assets/documents/nwgs/Li-andNie-translation-final-5-22-09.pdf (accessed July 2010).

26،“Treaty on the Prevention of the Placement of Weapons in Outer Space, the Threat or Use of Force against Space Objects,” (PPW) draft of 12 February 2008, http://www.mfa.gov.cn/eng/wjb/zzjg/jks/kjfywj/t408357.htm (accessed July 2010).

${ }^{27}$ Critics also objected to the draft PPW Treaty's lack of legally binding verification provisions and the Executive Organization with broad but unspecified powers to punish violations. The Bush Administration's response to the draft is "Letter dated 19 August 2008 from the Permanent Representative of the United States of America," CD/1847 (21 August 2008).

${ }^{28}$ Statement by the United States Delegation to the $64^{\text {th }}$ Session of the United National General Assembly's First Committee, 19 October 2009.

${ }^{29}$ Ibid., p. 5.

${ }^{30}$ U.S. National Space Policy,” Fact sheet released 6 October 2006, available at: http://www.nss.org/resources/library/spacepolicy/2006NationalSpacePolicy.htm

${ }^{31}$ Statement by the United States Delegation to the $64^{\text {th }}$ Session of the United National General Assembly's First Committee, 19 October 2009, p. 5.

${ }^{32}$ When asked whether the space policy reviews had given much consideration to formal arms control in space, Michael Nacht, U.S. Assistant Secretary of Defense for Global Strategic Affairs, said that the Obama Administration 
had been concentrating its arms control expertise on nuclear issues. He suggested that whatever additional space security cooperation the United States currently needed could be accomplished more easily through norms and Codes of Conduct that would not require ratification. The Chinese ASAT test had been a "wake up call," though, and if China or other countries continued to demonstrate new capabilities to interfere with U.S. space assets, Nacht implied that the United States might become more interested in formal arms control. "Space Policies for a Contested Global Commons,” presentation at the Henry L. Stimson Center, 12 May 2010.

${ }^{33}$ When the phrase "effectively verifiable" was coined by the Reagan Administration, it meant arrangements with a very high probability of detecting not only militarily significant violations, the standard then used for "adequate" verification, but also minor infractions. By the time that Reagan and George H. W. Bush Administration officials testified for ratification of the Intermediate Range Nuclear Forces Treaty and the Strategic Arms Reduction Treaties, their criteria for "effective verification" had returned to detecting militarily significant violations, but arms control opponents still try to set the standard for "effective" verification unrealistically high to block treaties they dislike for other reasons.

${ }^{34}$ The CFR Task Force on "U.S. Nuclear Weapons Policy” included Ashton Carter, Michelle Flournoy, and Franklin Miller. Its April 2009 report is at: http://www.cfr.org/publication/19226 (accessed July 2010).

${ }^{35}$ Alexei Arbatov, "Preventing an Arms Race in Outer Space," in Alexandre Kalliadine and Alexei Arbatov, eds., Russia: Arms Control, Disarmament, and International Security (Institute of World Economy and International Relations, 2010), http://www.imemo.ru/ru/publ/2010/10003.pdf (accessed July 2010).

36، On the Merits of Certain Draft Transparency and Confidence-Building Measures and Treaty Proposals for Space Security,” Canadian Working Paper, tabled at the Conference on Disarmament, 26 March 2009. For ways to build on this proposal, see Nancy Gallagher, "A Reassurance-based Approach to Space Security,” Report for the International Security Research and Outreach Program of the Department of Foreign Affairs and Trade Canada, October 2009, http://www.international.gc.ca/arms-armes/isrop-prisi/research-recherche/spaceespace/gallagher2009/index.aspx (accessed July 2010).

${ }^{37}$ Roger Harrison, et al., "Space Deterrence," Space and Defense 3:1 (Summer 2009): 1-30, http://web.mac.com/rharrison5/Eisenhower_Center_for_Space_and_Defense_Studies/Space_Deterrence.html (accessed September 2010).

${ }^{38}$ The 2010 National Space Policy mentions deterrence several times, but does not highlight it as the dominant principle guiding U.S. policy, in keeping with the more cooperative message that this document is meant to convey. ${ }^{39}$ For examples of global governance efforts on a wide range of issues, including weapons proliferation and warfare, communications, crime, global finance and trade, and environmental protection, see P.J. Simmons and Chantal de Jonge Oudraat, eds., Managing Global Issues (Carnegie Endowment for International Peace, 2001.)

${ }^{40}$ For various ways of making this argument, see America's Vision: The Case for Space Exploration (U.S. Space Foundation, 2006).

${ }^{41}$ "'Review of the implementation of the recommendations of the Third United Nations Conference on the Exploration and Peaceful Uses of Outer Space,” UNGA doc A/59/174, 23 July 2004, http://www.oosa.unvienna.org/pdf/reports/unispace/A_59_174E.pdf (accessed July 2010).

${ }^{42}$ National Security Strategy, May 2010, p. 40, http://www.whitehouse.gov/sites/default/files/rss_viewer/national_security_strategy.pdf.

${ }^{43}$ Steven Kull, et al., "Americans and Russians on Space Weapons," Joint study by WorldPublicOpinion.org and the Center for International and Security Studies at Maryland, 24 January 2008, http://www.worldpublicopinion.org/pipa/pdf/jan08/CISSM_Space_Jan08_rpt.pdf (accessed July 2010). 